\title{
COVID-19 and Cardiovascular Health Among Patients with Cancer
}

\author{
Nicolas L. Palaskas ${ }^{1}$ (D) Efstratios Koutroumpakis ${ }^{2} \cdot$ Anita Deswal $^{1}$ \\ Accepted: 9 September 2020 / Published online: 10 October 2020 \\ (C) Springer Science+Business Media, LLC, part of Springer Nature 2020
}

\begin{abstract}
Purpose of review The coronavirus disease 2019 (COVID-19) pandemic, caused by the severe acute respiratory syndrome coronavirus 2 (SARS-CoV-2), continues to spread with rising new cases and deaths. Patients with cancer represent a uniquely vulnerable population not only with higher susceptibility to COVID-19 but also at increased risk for its complications. This review focuses on the implications of COVID-19 in the cardiovascular health of patients with cancer.

Recent findings Patients more susceptible to COVID-19 with increased severity of disease include those with cancer and cardiovascular comorbidities. In addition, the cardiovascular complications of COVID-19 including acute myocardial injury, thromboembolism, cardiomyopathy, myocarditis, and pericardial disease overlap with many of those encountered during cancer treatment. Summary Despite the absence of large studies of patients with both cancer and cardiovascular disease, the incidence of cardiovascular complications in cancer patients with COVID-19 is expected to be high. This has implications for cardiac monitoring, chemotherapy administration, and the diagnosis and treatment of cardiovascular disease during COVID-19.
\end{abstract}

Keywords Coronavirus $\cdot$ Cardiovascular $\cdot$ Cancer $\cdot$ COVID-19

\section{Introduction}

Since its emergence from Wuhan, China, in December of 2019, the severe acute respiratory syndrome coronavirus 2 (SARS-CoV-2) has spread rapidly around the globe with 13 million confirmed cases and more than 570,000 deaths as of July 14, 2020 [1]. Multiorgan involvement, including cardiovascular system manifestations, has been associated with the novel coronavirus disease 2019 (COVID-19) or its treatment $[2,3]$. Acute myocardial injury, acute myocarditis, arrhythmias, and thromboembolic events have all been observed

This article is part of the Topical Collection on Cardio-Oncology

Nicolas L. Palaskas

nlpalaskas@mdanderson.org

Efstratios Koutroumpakis

Efstratios.Koutroumpakis@uth.tmc.edu

Anita Deswal

ADeswal@mdanderson.org

1 Department of Cardiology, University of Texas MD Anderson Cancer Center, 1400 Pressler Street, Unit 1451, Houston, TX 77025, USA

2 Division of Cardiovascular Medicine, University of Texas Health Science Center, Houston, TX, USA during COVID-19 infection [4-6]. The early experiences from China suggest that some patient characteristics (e.g., age, gender, pre-existing disease conditions including cardiovascular disease and cancer) as well as exposure to certain medications increase an individual's risk of COVID-19-related adverse outcomes [2].

Patients with cancer represent a unique population during the era of COVID-19 pandemic, not only because of their susceptibility to infections in the setting of a compromised immune system but also due to their already elevated risk for thromboembolic events, myocarditis in the setting of treatment with immune checkpoint inhibitors, and QT prolongation related to cancer therapeutics, all of which also represent known complications of COVID-19 and its treatment (Fig. 1). In the current review, we summarize existing evidence on the susceptibility of patients with cancer and/or cardiovascular disease to COVID-19 and its complications. We also elaborate on the impact of the COVID-19 pandemic on timely cardiovascular and cancer care.

\section{Pathophysiology of COVID-19}

Coronaviruses are single-stranded RNA viruses known to cause the common cold as well as being responsible for several outbreaks including the severe acute respiratory syndrome 


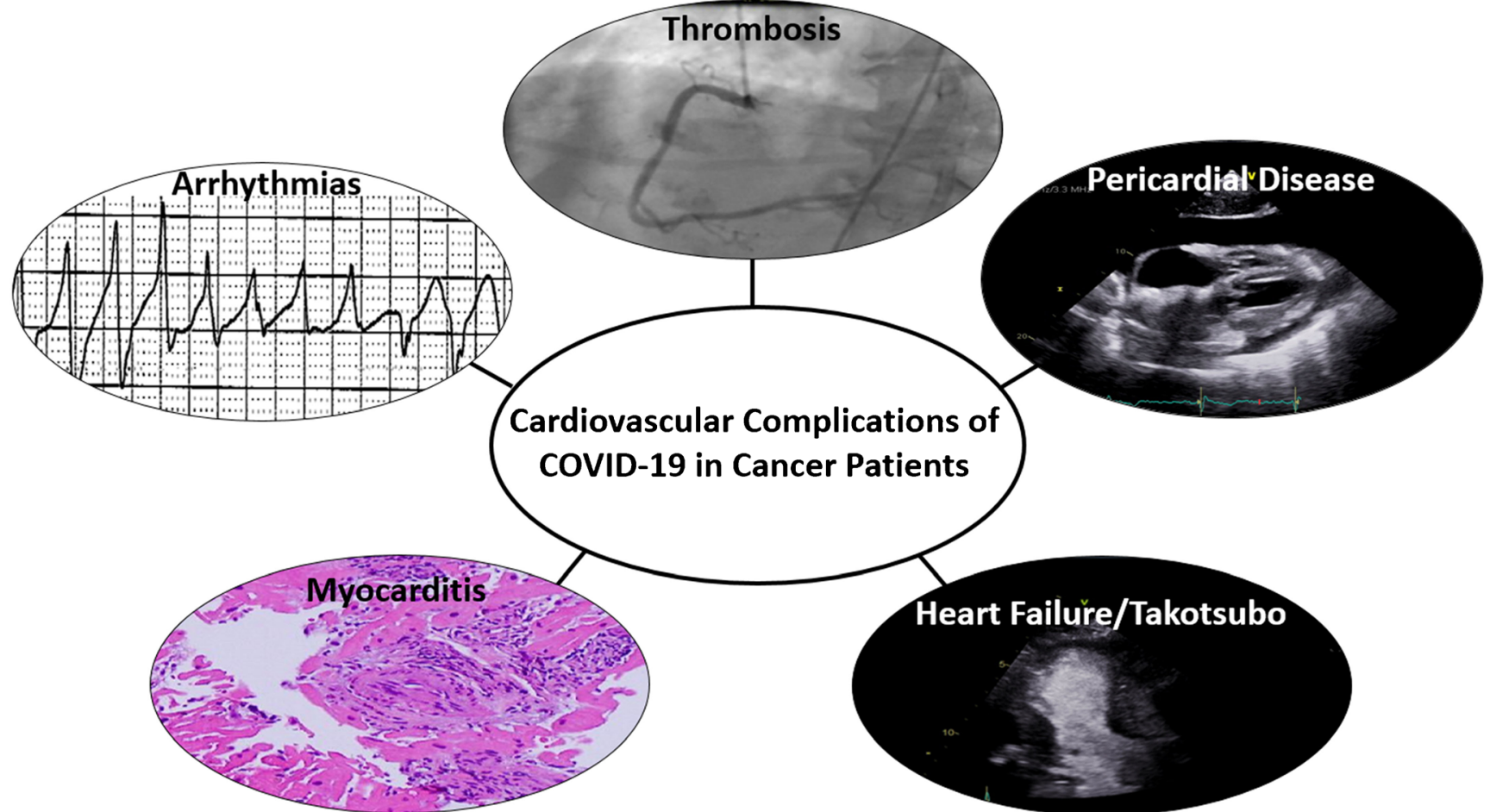

Fig. 1 Cardiovascular complications of COVID-19 in cancer patients. COVID-19, coronavirus disease 2019

(SARS) in 2002-2004, Middle East respiratory syndrome (MERS) in 2012-2013, and now the current SARS-CoV-2 outbreak causing COVID-19. The SARS-CoV-2 life cycle in human cells starts with binding to cell membrane receptors resulting in phagocytosis into cells. This is followed by the virus taking over cellular machinery to replicate itself. This eventually leads to the cell recognizing the process and initiating apoptosis thus leading to release of the replicated virus.

SARS-CoV-2 has spike (S) proteins on its cell surface that bind with high affinity to angiotensin-converting enzyme (ACE2) receptors. After binding, the viral cellular membrane fuses with the host cell membrane and the virus enters into the host cell $\left[7_{\bullet \bullet}\right]$. There are many human cells that express ACE2 receptors including the lung epithelium, which explains the local lung pathology caused by SARS-CoV-2 and its transmission through respiratory droplet and possibly, airborne pathways [8]. ACE2 receptors are also expressed by human cardiac cells and might be implicated in the mechanism of cardiac injury during COVID-19 infection $[8,9]$.

The host immune response to SARS-CoV-2 is likely a double-edged sword that is important in early control of the virus, but if unchecked can lead to increased tissue injury from the inflammatory response. Clinically a biphasic response has been observed that matches this early and late phase of immune response which has been associated with longer hospital stays [10]. Innate and adaptive immunity is involved in the SARS-CoV-2 immune response. Lymphopenia has been noted in those hospitalized with COVID-19 with reductions in absolute counts of CD4+ and CD8+ T cells. Along with this, a pro-inflammatory "cytokine storm" syndrome has been described with elevations in various cytokines, particularly interleukin-6 (IL-6), tumor necrosis factor $\alpha$ (TNF- $\alpha$ ), and granulocyte-macrophage colony-stimulating factor (GM-CSF) [11]. It is postulated that this leads to local lung tissue injury and systemic effects such as thrombosis and myocardial injury.

\section{Susceptibility of Patients with Cancer to COVID-19 and its Complications}

Patients with cancer are often immunocompromised due to the disease process itself and/or due to cancer treatment. As a result, patients with cancer are susceptible to infections and their complications [12]. Initial reports from China suggested that patients with COVID-19 were more likely to have a history of cancer compared with the general population, supporting a potential susceptibility of the cancer population to COVID-19 [13•]. Although patients with cancer are more likely to demonstrate behaviors of social distancing and wearing a mask, the reported infection rate of COVID-19 among cancer patients was double the rate of COVID-19 in the general population of Wuhan [14]. More specifically, among 1524 patients with cancer admitted to the Zhongnan Hospital in Wuhan, $0.79 \%$ had COVID-19. This infection rate was significantly higher than the cumulative incidence of all diagnosed COVID-19 cases that were reported in the city of Wuhan over the same time period $(0.37 \%$; OR of cancer 
history in patients with COVID-19 was estimated as 2.31, 95\% CI 1.89-3.02) [14].

Furthermore, reports from China also support that patients with cancer are at higher risk of COVID-19 complications. Patients with cancer infected with SARS-CoV-2 in Wuhan were significantly more likely to be admitted to the intensive care unit (ICU) or die compared with patients without cancer (39\% vs $8 \%$, respectively; $p<0.001$ ) [13•]. The case fatality rate was estimated at $5.6 \%$ in patients with cancer compared with $2.3 \%$ in the general population [15]. In another report from Wuhan, out of 28 patients with cancer and COVID-19, $54 \%$ required care in an intensive unit and 29\% died [16]. Furthermore, patients who received cancer treatments within the last 14 days required intensive care more frequently (hazard ratio [HR] 4.1, 95\% confidence interval $[\mathrm{CI}] 1.1-15.3, p=$ 0.037 ) [16]. It was suggested that not only patients actively treated for cancer but also cancer survivors are more susceptible to COVID-19 and its complications [13•, 14]. Although the above reports suggest an increased susceptibility of cancer patients to COVID-19 and its complications, they are based on observations of a small number of patients. A larger prospective study from the UK (United Kingdom Coronavirus Cancer Monitoring Project [UKCCMP]) included 800 cancer patients with COVID-19. Interestingly, $88 \%$ of patients were hospitalized. The mortality rate in that cohort was $28 \%$, while factors that increased the risk of death included advanced age (odds ratio [OR] 9.42, 95\% CI 6.56-10.02, $p<0.001$ ), male gender (OR 1.67, 95\% CI 1.19-2.34, $p=0.003$ ), history of hypertension (OR 1.95, 95\% CI 1.36-2.80, $p=0.002)$, and cardiovascular disease (OR 2.32, 95\% CI 1.47-3.64, $p=0.002$ ). These factors have similarly been associated with worse outcomes in the non-cancer population [17]. In contrast to the initial reports from China, the authors of the UKCCMP study reported that after adjusting for risk factors such as age and comorbidities, receiving cytotoxic chemotherapy within 4 weeks of developing COVID-19 had no significant effect on outcomes (OR $1.18,95 \%$ CI $0.81-1.72, n=281$ ) [18•]. Furthermore, compared with patients not on these therapies, patients on immunotherapy (OR $0.59,95 \%$ CI $0.27-1.27, n=44$ ), hormonal therapy $(0.90,95 \%$ CI $0.49-1.68, n=64)$, radiotherapy $(0.65$ $[0.36-1.18], n=76)$, and targeted therapies $(0.83,95 \% \mathrm{CI}$ $0.45-1.54, n=72$ ) did not demonstrate an increased risk of mortality. The numbers in the subgroups are smaller, and more data is needed to better define the susceptibility risk and outcomes of cancer patients to SARS-CoV-2, and its association with recent cancer therapy.

\section{Cardiovascular Comorbidities and Risk of COVID-19}

Cancer and cardiovascular disease have many shared risk factors including but not limited to hypertension, diabetes, and obesity [19]. Recent studies suggest that patients with these risk factors are more likely to develop COVID-19 and have a more severe disease course. One of the initial studies out of China, including 138 hospitalized patients with COVID-19, reported that $31.1 \%$ had a baseline diagnosis of hypertension, while $14.1 \%$ had a baseline diagnosis of cardiovascular disease. Furthermore, patients with baseline hypertension, diabetes, cardiovascular disease, or cerebrovascular disease were more likely to need ICU care [20]. Similar results were reproduced by $\mathrm{Li}$ et al. in a meta-analysis of 6 studies comprising of 1527 patients. Hypertension was the most common comorbidity which was found in $17.1 \%$ of patients followed by cardio-cerebrovascular disease at $16.4 \%$, and diabetes in $9.7 \%$ of patients with COVID-19. In addition, having these comorbidities resulted in a two- to threefold increased risk of requiring admission to an ICU [21]. Beyond having a more severe disease course requiring ICU stays, those with hypertension, coronary heart disease, and diabetes are also more likely to die with COVID-19 with higher rates of acute myocardial injury [22]. These findings were further supported by two large cohort studies. In the UKCCMP study, increased mortality was associated with history of hypertension (OR $1.95,95 \%$ CI $1.36-2.80, p=0.002)$ and cardiovascular disease (OR 2.32, 95\% CI 1.47-3.64, $p=0.002$ ). A large multicenter study from the USA, Canada, and Spain, which included 928 cancer patients with COVID-19, reported that independent factors associated with death included increased age (per 10 years; partially adjusted OR $1.84,95 \%$ CI 1.53-2.21), male gender (1.63, 1.07-2.48), smoking status (former smoker vs never smoked: 1.60, 1.03-2.47), and number of comorbidities (two vs none: 4.50, 1.33-15.28) [23].

Interestingly, it was noted that patients with more severe illness in the ICU also had statistically higher blood pressures. One of the initial reports reported an average systolic blood pressure of $145 \mathrm{mmHg}$ for those in the ICU, compared with hospitalized patients outside of intensive care with average systolic blood pressure of $122 \mathrm{mmHg}$ ( $p$ value 0.017 ) [2] The elevation in blood pressure for those with more severe illness was postulated to be secondary to alterations in the renin-angiotensin-aldosterone system due to entry of SARS-CoV-2 through the ACE2 receptor. The hypothesis is that binding of a high viral load to ACE2 receptors results in down-regulation of the ACE2 receptor on host cell walls. ACE2 is responsible for the conversion of angiotensin I to angiotensin $(1,9)$ and angiotensin II to angiotensin $(1,7)$. Therefore, with down-regulation of ACE2, it was postulated that there are increased levels of angiotensin contributing to increased blood pressure during illness and potentially worse outcomes due to angiotensin's effect on acute lung injury, adverse cardiac remodeling, vasoconstriction, and vascular permeability [24]. This further led to early theoretical concerns that use of the common antihypertensive classes, angiotensin-converting enzyme inhibitors and angiotensin receptor blockers (ACEI/ARB) could potentially exacerbate this harmful effect. Soon after, the Heart Failure Society of 
America, American College of Cardiology, and the American Heart Association released a joint statement regarding the lack of data for beneficial or harmful outcomes with the use of ACEI/ARB and that patients should be continued on these medications when prescribed for indications such as heart failure, hypertension, or ischemic heart disease, pending further data [25]. This was followed by a large retrospective cohort of almost 5000 patients with COVID-19 in which $20 \%$ were on ACEI/ARB. After matching for confounders such as age and comorbidities, it was found that those on ACEI/ARB had similar outcomes with an adjusted HR of 0.83 (95\% CI 0.67-1.03) [26]. Another retrospective study found beneficial outcomes for patients on ACEI/ARB with an adjusted HR of 0.42 (95\% CI $0.15-0.89, p$ value 0.03 ). In addition, patients with baseline hypertension on ACEI/ARB had a mortality benefit when compared with other antihypertensives (adjusted HR 0.30, 95\% CI 0.12-0.70, $p=$ 0.01 ) [27•]. Given patients with cancer have cardiovascular comorbidities, and the encouraging observational data, patients already on ACEIs and ARBs who contract COVID-19 should be continued on these agents unless they are acutely ill with lower blood pressures or frank hypotension.

\section{Myocardial Injury in Patients with COVID-19 and Cancer}

Myocardial injury in cancer patients can have many different etiologies; these include, but are not limited to, acute coronary syndrome, type II myocardial infarction, myocarditis, and stress cardiomyopathy [28]. The reporting of cardiovascular complications in patients with cancer and COVID-19 is limited (Table 1), but many studies have separately described either cancer patients or cardiovascular disease. The National Health Commission of China documented that approximately $12 \%$ of patients without prior cardiovascular disease (CVD), who expired in the setting of COVID-19, had either elevated cardiac troponin I levels or a cardiac arrest during hospitalization [6]. Guo et al. demonstrated that $27.8 \%$ of patients with COVID-19 had myocardial injury as defined by elevation in troponin $\mathrm{T}[7 \cdot \bullet$ ], while another retrospective study of 416 patients found that $19.7 \%$ developed acute myocardial injury. Those with myocardial injury were more likely to have comorbidities, more often required non-invasive and/or invasive ventilation, and had higher mortality [34]. Zhou et al. found one of the most marked differences in acute myocardial injury in which $59 \%$ of non-survivors were found to have acute myocardial injury compared with only $1 \%$ of survivors [22]. Also, we have previously found that when patients with cancer present with troponin elevation and possible acute coronary syndrome, the majority are confirmed to have type II myocardial infarction [35]. Therefore, in alignment with recommendations of cardiac societies, we suggest that troponin levels should only be checked in patients with cancer and COVID-19 if significant cardiac involvement in the form of acute coronary syndrome or myocarditis is suspected, and if the findings of troponin elevation would change management [36]. Furthermore, even in the setting of ST elevation myocardial infarction (STEMI), defined as typical symptoms with localized ST segment elevation or new left bundle branch block, up to $40 \%$ of COVID-19 patients did not have an identifiable culprit artery on angiography [37]. This is clinically relevant, given that many hospitals have been using fibrinolytics as first-line treatment for COVID-19 patients presenting with STEMI, partly due to infection control logistics for cardiac catheterization laboratories during the COVID-19 pandemic and to reduce the exposure of health care personnel to SARS-CoV-2 [38]. However, cancer patients typically have absolute or relative contraindications to fibrinolytic therapy with a higher risk of bleeding with administration of these agents, and if a significant proportion may not have an acute thrombotic coronary event requiring revascularization, an upfront invasive strategy may be more appropriate, to determine the etiology and correctly manage the STEMI-like presentation in this population.

\section{Stress Cardiomyopathy in Patients with COVID-19 and Cancer}

The incidence of stress cardiomyopathy (SCM), or Takutsubo syndrome, has been reported to be higher in patients with cancer than the general population. In an analysis of the InterTAK (International Takotsubo) Registry, a large, multicenter Takotsubo syndrome population database, $16.6 \%$ of 1604 patients with SCM carried the diagnosis of cancer [39]. Similarly, Tornvall et al. reported that among 505 patients with SCM, $14.3 \%$ had a history of malignancy compared with $11.0 \%$ of 1007 controls $(p=0.07)$ [40]. In a meta-analysis study by Brunetti et al., including 123,563 patients with SCM, cancer was associated with development of adverse clinical outcomes including arrhythmias, cardiogenic shock, thromboembolism, and need for respiratory support [41]. Reported triggers of SCM in cancer patients include the emotional stress related to diagnosis and prognosis of cancer and the physical stress from cancer itself or its treatments [42].

Similar to cancer, COVID-19 causes significant emotional and physical stress to affected individuals. A retrospective study of 1914 patients by Jabri et al. reported a significant increase in the incidence of SCM during the COVID-19 period compared with the pre-pandemic time (7.8\% vs $1.5-1.8 \%$, respectively, $p<0.001$ ) [43]. Although there is no published data at the time of this review regarding the incidence of SCM in patients with cancer and COVID-19, it is suspected to be increased due to the combination of these two risk factors. 
Table 1 Epidemiologic studies reporting data on cancer patients with COVID-19

\begin{tabular}{|c|c|c|c|c|c|c|}
\hline Author & Journal & $\begin{array}{l}\text { Publication } \\
\text { date }\end{array}$ & Location & $\begin{array}{l}\text { Total number of } \\
\text { patients with } \\
\text { COVID-19 }\end{array}$ & $\begin{array}{l}\text { Number of cancer } \\
\text { patients with } \\
\text { COVID-19 }\end{array}$ & $\begin{array}{l}\text { Number of cancer patients } \\
\text { with COVID-19 and elevated } \\
\text { cardiac biomarkers or adverse } \\
\text { cardiac events }\end{array}$ \\
\hline Liang $W$ et al. $[13 \bullet \bullet]$ & Lancet Oncology & $03 / 2020$ & China & 1590 & 18 & Not reported \\
\hline Yu J et al. [14] & JAMA Oncology & $03 / 2020$ & Wuhan, China & 1524 & 12 & Not reported \\
\hline Zhang L et al. [16] & Annals of Oncology & $03 / 2020$ & Wuhan, China & 28 & 28 & 1 (acute myocardial infarction) \\
\hline Dai M et al. [29] & Cancer Discovery & $04 / 2020$ & $\begin{array}{l}\text { Hubei Province, } \\
\text { China }\end{array}$ & 641 & 105 & Not reported \\
\hline Lee LYW et al. [18•] & Lancet & $05 / 2020$ & UK & 800 & 800 & Not reported \\
\hline Kuderer NM et al. [23] & Lancet & $05 / 2020$ & USA, Canada, Spain & 928 & 928 & Not reported \\
\hline Bogani $G$ et al. [30] & $\begin{array}{r}\text { Gynecologic } \\
\text { Oncology }\end{array}$ & $06 / 2020$ & Milan, Italy & 355 & 19 & Not reported \\
\hline Pinato DJ et al. [31] & Cancers & $07 / 2020$ & UK, Italy, Spain & 204 & 204 & 3 (acute cardiac injury) \\
\hline $\begin{array}{l}\text { Garassino } \\
\quad \text { MC et al. [32] }\end{array}$ & Lancet Oncology & $07 / 2020$ & Europe & 200 & 200 & 1 (heart failure) \\
\hline Mehta et al. [33] & Cancer Discovery & $07 / 2020$ & New York & 218 & 218 & Not reported \\
\hline
\end{tabular}

\section{Thromboembolism in Patients with COVID-19 and Cancer}

The prothrombotic state of patients with cancer and side effects of certain cancer therapeutics, such as vascular endothelial pathway inhibitors, proteasome inhibitors, radiotherapy, and fluoropyrimidines, place these patients at higher risk for both venous and arterial thromboembolism [44]. In general, the rates of myocardial infarction and stroke have been shown to be higher in patients with cancer compared with non-cancer patients [45]. In addition to cancer increasing the risk of thromboembolism, there have been reports of pulmonary embolism and increased thromboembolic risk with severe infections and COVID-19 [46]. Furthermore, a report from 2 Dutch hospitals, including 184 ICU patients with COVID-19, reported that the incidence rate of thromboembolic events among these patients was $31 \%$ (27\% venous, $4 \%$ arterial) [47]. Thromboembolic events included pulmonary embolism, deep-vein thrombosis, ischemic stroke, myocardial infarction, or systemic arterial embolism [47]. There is suspected microvascular and macrovascular dysfunction that occurs with COVID-19, with endothelial involvement by the virus [48]. Elevations in d-dimer with mild reductions in platelet counts and a coagulation disorder resembling disseminated intravascular coagulation are observed with COVID-19 infection [49, 50]. In addition, the presence of these coagulation abnormalities has been associated with worse clinical outcomes $[49,50]$. Several venous thromboembolism prophylaxis anticoagulation strategies have been applied to patients with COVID-19 but whether these should be modified for those with cancer is unclear [51].

Furthermore, whether therapeutic doses of anticoagulation, given prophylactically, will prevent adverse outcomes in patients with COVID-19 is unknown. Two retrospective studies compared patients with COVID-19 who received therapeutic dose anticoagulation vs those who did not $[52,53]$. Although both failed to show a difference in mortality, a sub-analysis showed possible mortality benefit among patients with severe disease and abnormal coagulation biomarkers (platelets, prothrombin time, d-dimmers) [52, 53]. However, it is not known how many of these patients had underlying thrombotic events already, and whether the therapeutic dose of anticoagulation was given truly prophylactically. The benefit of prophylactic therapeutic dose anticoagulation is not known presently but studies are ongoing.

Cancer carries the paradox of having an increased thrombotic risk at the same time as conferring an increased bleeding risk. A common tool for the use of venous thromboembolism prophylaxis in patients with cancer is the Khorana score; however, its applicability to those with COVID-19 is not studied [54]. Thus, although large studies of patients with cancer and COVID-19 are missing, it is expected that the incidence of thromboembolism will be higher in those patients compared with the general population of COVID-19 patients. Therefore, a higher level of vigilance along with prophylactic dose anticoagulation in most hospitalized COVID-19 cancer patients, unless contraindicated due to high risk of bleeding, may be prudent, based on general guidance in all hospitalized COVID-19 patients [55].

\section{Myocarditis in Patients with COVID-19 who are Treated with immune Checkpoint Inhibitors}

Immune checkpoint inhibitors (ICI) are used in several malignancies, and as front-line therapy in some [56]. While promising in their cancer efficacy, these drugs have led to the emergence of immune-related adverse events (irAE) including the 
severe, albeit uncommon, event of ICI myocarditis. Cardio-oncology centers are well aware of ICI myocarditis, especially given a high reported mortality rate of $25-50 \%$ [46]. Blockade of immune checkpoints allows $\mathrm{T}$ cells in the immune system to become activated and attack tumor cells. Due to molecular mimicry and shared epitopes between tumor and cardiac substructures, the activated T cells can also attack the myocardium leading to an autoimmune myocarditis. In addition to the increased risk of ICI myocarditis among patients with cancer, there have also been increasing reports that COVID-19 is associated with the development of myocarditis, with one autopsy report suggesting an inflammatory cellular infiltrate similar to that seen in ICI myocarditis $[6,57]$. There are even reports of successfully treating COVID-19 myocarditis with immunomodulation, glucocorticoids, and human immunoglobulin, which is similar to the various immunomodulatory therapies used by cardio-oncologists to treat ICI myocarditis [5, 58]. Given these similarities, identifying whether ICI vs COVID-19, vs the combination of the two, is the cause of myocarditis in SARs-CoV-2 positive patients, who have received ICI, may be challenging. It is also unknown if ICI therapy will allow for unregulated $\mathrm{T}$ cells to cause an increased frequency of myocarditis in COVID-19 patients with cancer. This has led some academic centers to hold doses of ICI during the COVID-19 pandemic or testing patients for COVID-19 prior to starting ICI, depending on the clinical scenario and indication for ICI [59]. One study demonstrated that patients with cancer had a more severe course of COVID-19 if the patient had received ICI within the prior 90 days [60]. This was contrasted by the UKCCMP prospective study of 800 patients with cancer and COVID-19 which demonstrated no higher risk for poor outcomes with COVID-19 in those who had received immunotherapy within the prior 4 weeks [18•]. Further systematic research is needed to identify whether this particular cancer therapy has an effect on the course of disease with SARs-CoV-2 and on irAEs, including myocarditis. Until such data become available, the potential risks of initiating or continuing this therapy will have to be weighed against the potential adverse effects on the progression of cancer in individual patients. Of course, if a patient on such therapy or any cancer chemotherapy or radiation therapy develops COVID-19, the cancer treatments are held until complete clinical recovery of the patient, and if possible until the community risk of infection decreases.

\section{Pericardial Disease in Patients with COVID-19 and Cancer}

There are case reports describing pericardial involvement of patients presenting with COVID-19 that range from pericarditis to pericardial tamponade [5, 61, 62]. Many of the cases describe acute myocardial injury in addition to a decline in left ventricular ejection fraction at the same time as the development of a large pericardial effusion causing cardiac tamponade. It is suspected that the patients developed myopericarditis due to COVID-19 [61, 62]. There are currently no large studies evaluating the incidence of pericardial effusion or pericarditis in patients with COVID-19. Patients with cancer can develop pericardial disease from either cancer itself or cancer therapeutics with cardiac tamponade also occurring $[63,64]$. In patients with cancer and COVID-19, it may be challenging to differentiate whether pericardial disease is due to the cancer, COVID-19, or a combination of the two. Regardless of the etiology, if patients are presenting with tamponade, pericardiocentesis should be performed emergently. If signs of pericarditis are present then providers should consider initiating anti-inflammatory medications such as non-steroidal anti-inflammatory drugs and/or colchicine with steroids reserved for refractory disease.

\section{QT Prolongation and Ventricular Arrhythmias in Patients with COVID-19 and Cancer}

Cancer patients are treated with numerous medications and many of them cause QT prolongation such as tyrosine kinase inhibitors, histone deacetylase inhibitors, arsenic trioxide, antiemetics, antidepressants, and anxiolytics [65]. Furthermore, the medications that received emergency use approval by the United States Food and Drug Administration (FDA) for treatment of COVID-19, including hydroxychloroquine, chloroquine, and azithromycin as well as the antivirals such as lopinavir/ritonavir are all known to cause QT prolongation [66•]. QT prolongation can increase the risk of development of torsades de pointes [67]. Thus, patients with cancer already on QT prolonging medications, receiving the above named empiric therapies for COVID-19, would likely be at an increased risk of this fatal arrhythmia. The effect on QTc prolongation was described in an observational study of $90 \mathrm{pa}-$ tients with COVID-19 (no data on cancer in this cohort). Those receiving concomitant hydroxychloroquine and azithromycin had a greater increase in QT interval (median $23 \mathrm{msec}$, interquartile range $10-40 \mathrm{msec}$ ) compared with those receiving hydroxychloroquine alone $(5.5 \mathrm{msec},(-15.5$ to $34.25 \mathrm{msec}) ; p=.03$ ). Of the 37 patients who were treated with hydroxychloroquine monotherapy, 7 patients had QTc prolongation to $>500 \mathrm{msec}$; of the 53 patients treated with the combination of hydroxychloroquine and azithromycin, 11 patients developed QTc $>500 \mathrm{msec}$. Also, the likelihood of prolonged QTc was greater in those who received concomitant loop diuretics (adjusted OR 3.38, 95\% CI 1.03-11.08) or had a baseline QTc of 450 msec or more (adjusted OR 7.11, 95\% CI 1.75-28.87). Of the 90 patients, one developed torsades de pointes and had recurrent ventricular arrhythmias which needed treatment with lidocaine [66•]. Since then the FDA has revoked the emergency use authorization for these agents, given data suggesting that hydroxychloroquine or 
chloroquine has no benefit in COVID-19 and, in observational studies, may be associated with higher mortality [68-70]. Remdesivir is an antiviral therapy that has demonstrated a decrease in time to recovery for patients with COVID-19. However, QT prolongation has not been described with remdesivir. In a randomized controlled trial of 1063 patients receiving remdesivir for COVID-19, no arrhythmias were observed but data regarding QT prolongation and monitoring were not reported [71]. How cancer, cancer therapies, and polypharmacy often associated with cancer will impact the rate of QTc prolongation, and clinically significant arrhythmias is unclear at this time but caution in this patient population with close cardiac monitoring while on COVID-19 treatment is warranted, especially given potential cardiac involvement with the infection.

\section{Cardiovascular Monitoring of Cancer Patients During COVID-19 Pandemic}

Cardiovascular disease is a common cause of death among cancer survivors [72]. Therefore, cardiovascular screening and surveillance strategies are used to monitor patients with cancer. However, not every cancer patient needs the same rigorous cardiovascular screening and surveillance strategy. In a retrospective study of 448 patients with breast cancer, routine cardiac imaging after treatment with trastuzumab led to changes in care of only $2.8 \%$ of patients [73]. This becomes especially important during COVID-19 pandemic, when the risk of spreading the SARS-CoV-2 virus among immunocompromised patients with cancer, during in-person visits for cardiovascular screening, may outweigh the benefit for all patients. Limiting cardiovascular screening to only high-risk patients, such as those with a history of cardiovascular disease, cardiovascular comorbidities, or advanced age, is prudent. Modified protocols to reduce the frequency of cardiac imaging surveillance for cancer patients during the COVID-19 pandemic, stressing the above principles, have been suggested [74].

\section{Prevention of COVID-19 in Cancer Patients with Cardiovascular Disease}

Cancer patients, especially those with underlying cardiovascular risk factors or cardiovascular disease, represent a high-risk group for COVID-19 infection and its complications as outlined above. Strict precautions for the prevention of COVID-19 in cancer patients are of the utmost importance. Implementation of infection control measures among cancer patients and cancer providers, including screening for symptoms, travel, or family members with COVID-19, universal use of face masks by patients and providers, as well as social distancing in waiting rooms, establishment of telehealth, no visitor policies in the hospitals, quarantine policies, and testing asymptomatic patients for SARS-CoV-2 before procedures, such as stem cell transplant or initiation of chemotherapy, as well as before aerosol generating procedures are some of the preventive measures that several cancer centers have adopted [75]. However, it should be emphasized to patients that concerns about acquiring COVID-19 should not be the reason for delays in seeking medical care. During the COVID-19 pandemic, late presentations of patients with acute myocardial infarction and subsequent development of complications or even death have been reported [76]. Although this observation can be attributed to several factors, patient fears of exposure to SARS-CoV-2 on presentation to health care facilities is one of them. This fear could be even more prevalent among high-risk patients such as those with cancer.

\section{Lessons Learned from CAR T Cell Therapy Provide Insights for the Treatment of COVID-19 in High-Risk Patients}

Chimeric antigen receptor (CAR) T cell therapy has emerged as a standard and potentially curative approach for pediatric $\mathrm{B}$ cell acute lymphoblastic leukemia and adult B cell non-Hodgkin lymphomas [77]. One of the common toxicities associated with CAR T cell therapy is cytokine release syndrome (CRS) [78]. IL-6 is a chemokine associated with inflammation and plays a key role in the pathophysiology of CRS that follows CAR T cell therapies [78]. Tocilizumab, a monoclonal antibody targeting the IL-6 receptor, has been shown to be effective against CRS and is approved by the FDA for treatment of severe or life-threatening CAR T cell therapy-associated CRS [79].

Observational studies in patients with COVID-19 inflammatory manifestations have demonstrated elevated cytokine levels, including IL-6, similar to patients with CRS post CAR T cell therapy. A meta-analysis of 9 studies, including 1426 patients with COVID-19, showed that elevated IL-6 levels were associated with more severe disease course and higher mortality [80]. Given the similarities with CRS post CAR T cell therapy, tocilizumab has been proposed as a treatment for severe COVID-19. In a large, retrospective, case-control study of 544 patients admitted to the hospital with severe COVID-19, treatment with tocilizumab correlated with a reduced risk of mechanical ventilation or death (adjusted HR $0.61,95 \%$ CI $0.40-0.92 ; p=0.02$ ) [81]. Multiple ongoing clinical trials aim to confirm the above findings and establish the clinical benefit of tocilizumab or other IL-6 receptor antagonists in high-risk patients with COVID-19, including those with cardiovascular comorbidities [82].

\section{Conclusions}

Increasing reports support that patients with cancer are at increased risk of infection with SARS-CoV-2 as are patients 
with baseline cardiac comorbidities. Given that older patients with cancer often have cardiovascular disease, this population remains vulnerable to contract COVID-19 as well as have worse outcomes. Large studies are needed to better define the magnitude of the risk and to tailor treatment for this select group.

\section{Acknowledgments none}

\section{Compliance with Ethical Standards}

Conflict of Interest Anita Deswal reports other from NIH (Site PI for NIH trial: INVESTED).

Human and Animal Rights and Informed Consent This article does not contain any studies with human or animal subjects performed by any of the authors.

\section{References}

Papers of particular interest, published recently, have been highlighted as:

- Of importance

•. Of major importance

1. Retrieved from : https://coronavirus.jhu.edu/map.html. Date retrieved: Accessed 18 July 2020.

2. Huang C, Wang Y, Li X, Ren L, Zhao J, Hu Y, et al. Clinical features of patients infected with 2019 novel coronavirus in Wuhan, China. Lancet. 2020;395(10223):497-506. https://doi. org/10.1016/s0140-6736(20)30183-5.

3. Xiong TY, Redwood S, Prendergast B, Chen M. Coronaviruses and the cardiovascular system: acute and long-term implications. Eur Heart J. 2020;41:1798-800. https://doi.org/10.1093/eurheartj/ ehaa231.

4. Hu H, Ma F, Wei X, Fang Y. Coronavirus fulminant myocarditis saved with glucocorticoid and human immunoglobulin. Eur Heart J. 2020. https://doi.org/10.1093/eurheartj/ehaa190.

5. Inciardi RM, Lupi L, Zaccone G, Italia L, Raffo M, Tomasoni D, et al. Cardiac involvement in a patient with coronavirus disease 2019 (COVID-19). JAMA Cardiol. 2020;5:819-24. https://doi. org/10.1001/jamacardio.2020.1096.

6. Xu Z, Shi L, Wang Y, Zhang J, Huang L, Zhang C, et al. Pathological findings of COVID-19 associated with acute respiratory distress syndrome. Lancet Respir Med. 2020;8(4):420-2. https://doi.org/10.1016/s2213-2600(20)30076-x.

7.• Li W, Moore MJ, Vasilieva N, Sui J, Wong SK, Berne MA, et al. Angiotensin-converting enzyme 2 is a functional receptor for the SARS coronavirus. Nature. 2003;426(6965):450-4. https://doi.org/ 10.1038 /nature 02145 . This is the first study to show the pathophysiologic mechanism of the SARS-CoV S protein and the $A C E 2$ receptor binding.

8. Li M-Y, Li L, Zhang Y, Wang X-S. Expression of the SARS-CoV2 cell receptor gene ACE2 in a wide variety of human tissues. Infect Dis Poverty. 2020;9(1):45. https://doi.org/10.1186/s40249-02000662-x.

9. Chen L, Li X, Chen M, Feng Y, Xiong C. The ACE2 expression in human heart indicates new potential mechanism of heart injury among patients infected with SARS-CoV-2. Cardiovase Res. 2020;116(6):1097-100. https://doi.org/10.1093/cvr/cvaa078.

10. Chen J, Qi T, Liu L, Ling Y, Qian Z, Li T, et al. Clinical progression of patients with COVID-19 in Shanghai, China. J Infect. 2020;80 (5):e1-6. https://doi.org/10.1016/j.jinf.2020.03.004.

11. Catanzaro M, Fagiani F, Racchi M, Corsini E, Govoni S, Lanni C. Immune response in COVID-19: addressing a pharmacological challenge by targeting pathways triggered by SARS-CoV-2. Signal Transduct Target Ther. 2020;5(1):84. https://doi.org/10. 1038/s41392-020-0191-1.

12. Kamboj M, Sepkowitz KA. Nosocomial infections in patients with cancer. Lancet Oncol. 2009;10(6):589-97. https://doi.org/10.1016/ s1470-2045(09)70069-5.

13. Liang W, Guan W, Chen R, Wang W, Li J, Xu K, et al. Cancer patients in SARS-CoV-2 infection: a nationwide analysis in China. Lancet Oncol. 2020;21(3):335-7. https://doi.org/10.1016/s14702045(20)30096-6. This is one of the initial and largest cohorts evaluating the risk of SARS-CoV 2 infection in cancer patients.

14. Yu J, Ouyang W, Chua MLK, Xie C. SARS-CoV-2 transmission in patients with cancer at a tertiary care hospital in Wuhan, China. JAMA Oncol. 2020;6:1108-10. https://doi.org/10.1001/ jamaoncol.2020.0980.

15. Wu Z, McGoogan JM. Characteristics of and important lessons from the coronavirus disease 2019 (COVID-19) outbreak in China: summary of a report of 72314 cases from the Chinese Center for Disease Control and Prevention. JAMA. 2020;323: 1239-42. https://doi.org/10.1001/jama.2020.2648.

16. Zhang L, Zhu F, Xie L, Wang C, Wang J, Chen R, et al. Clinical characteristics of COVID-19-infected cancer patients: a retrospective case study in three hospitals within Wuhan, China. Ann Oncol. 2020;31:894-901. https://doi.org/10.1016/j.annonc.2020.03.296.

17. Richardson S, Hirsch JS, Narasimhan M, Crawford JM, McGinn T, Davidson KW, et al. Presenting characteristics, comorbidities, and outcomes among 5700 patients hospitalized with COVID-19 in the New York City area. JAMA. 2020;323(20):2052-9. https://doi.org/ 10.1001/jama.2020.6775.

18.• Lee LYW, Cazier JB, Starkey T, Turnbull CD, Kerr R, Middleton G. COVID-19 mortality in patients with cancer on chemotherapy or other anticancer treatments: a prospective cohort study. Lancet. 2020;395(10241):1919-26. https://doi.org/10.1016/s0140-6736 (20)31173-9. This study reported on the risk of worse outcomes for patients with cancer who received recent cancer therapeutics.

19. Koene RJ, Prizment AE, Blaes A, Konety SH. Shared risk factors in cardiovascular disease and cancer. Circulation. 2016;133(11): 1104-14. https://doi.org/10.1161/circulationaha.115.020406.

20. Wang D, Hu B, Hu C, Zhu F, Liu X, Zhang J, et al. Clinical characteristics of 138 hospitalized patients with 2019 novel coronavirus-infected pneumonia in Wuhan, China. JAMA. 2020;323(11):1061-9. https://doi.org/10.1001/jama.2020.1585.

21. Li B, Yang J, Zhao F, Zhi L, Wang X, Liu L, et al. Prevalence and impact of cardiovascular metabolic diseases on COVID-19 in China. Clin Res Cardiol. 2020;109(5):531-8. https://doi.org/10. 1007/s00392-020-01626-9.

22. Zhou F, Yu T, Du R, Fan G, Liu Y, Liu Z, et al. Clinical course and risk factors for mortality of adult inpatients with COVID-19 in Wuhan, China: a retrospective cohort study. Lancet. 2020;395 (10229):1054-62. https://doi.org/10.1016/s0140-6736(20)305663.

23. Kuderer NM, Choueiri TK, Shah DP, Shyr Y, Rubinstein SM, Rivera DR, et al. Clinical impact of COVID-19 on patients with cancer (CCC19): a cohort study. Lancet. 2020;395(10241):190718. https://doi.org/10.1016/s0140-6736(20)31187-9.

24. Vaduganathan M, Vardeny O, Michel T, McMurray JJV, Pfeffer MA, Solomon SD. Renin-angiotensin-aldosterone system 
inhibitors in patients with Covid-19. N Engl J Med. 2020;382(17): 1653-9. https://doi.org/10.1056/NEJMsr2005760.

25. Biykem Bozkurt RK, Bob Harrington. March 17th, 2020. Retrieved from: https://www.acc.org/latest-in-cardiology/articles/2020/03/17/ 08/59/hfsa-acc-aha-statement-addresses-concerns-re-using-raasantagonists-in-covid-19 Accessed 15 July 2020.

26. Fosbøl EL, Butt JH, Østergaard L, Andersson C, Selmer C, Kragholm K, et al. Association of angiotensin-converting enzyme inhibitor or angiotensin receptor blocker use with COVID-19 diagnosis and mortality. JAMA. 2020;324(2):168-77. https://doi.org/ 10.1001/jama.2020.11301.

27. Zhang P, Zhu L, Cai J, Lei F, Qin J-J, Xie J, et al. Association of inpatient use of angiotensin-converting enzyme inhibitors and angiotensin II receptor blockers with mortality among patients with hypertension hospitalized with COVID-19. Circ Res. 2020;126 (12):1671-81. https://doi.org/10.1161/CIRCRESAHA.120. 317134. One of the first studies to evaluate whether the theoretical risk of taking an ACEI/ARB had worse outcomes after developin COVID-19.

28. Iliescu CA, Grines CL, Herrmann J, Yang EH, Cilingiroglu M, Charitakis K, et al. SCAI Expert consensus statement: evaluation, management, and special considerations of cardio-oncology patients in the cardiac catheterization laboratory (endorsed by the cardiological society of india, and sociedad Latino Americana de Cardiologia intervencionista). Catheter Cardiovasc Interv. 2016;87 (5):E202-23. https://doi.org/10.1002/ccd.26379.

29. Dai M, Liu D, Liu M, Zhou F, Li G, Chen Z, et al. Patients with cancer appear more vulnerable to SARS-CoV-2: a multicenter study during the COVID-19 outbreak. Cancer Discov. 2020;10 (6):783-91. https://doi.org/10.1158/2159-8290.Cd-20-0422.

30. Bogani G, Ditto A, Bosio S, Brusadelli C, Raspagliesi F. Cancer patients affected by COVID-19: experience from Milan, Lombardy. Gynecol Oncol. 2020;158:262-5. https://doi.org/10.1016/j.ygyno. 2020.06.161.

31. Pinato DJ, Lee AJX, Biello F, Seguí E, Aguilar-Company J, Carbó $\mathrm{A}$, et al. Presenting features and early mortality from SARS-CoV-2 infection in cancer patients during the initial stage of the COVID-19 pandemic in Europe. Cancers. 2020;12(7). https://doi.org/10.3390/ cancers12071841.

32. Garassino MC, Whisenant JG, Huang LC, Trama A, Torri V, Agustoni F, et al. COVID-19 in patients with thoracic malignancies (TERAVOLT): first results of an international, registry-based, cohort study. Lancet Oncol. 2020;21(7):914-22. https://doi.org/10. 1016/s1470-2045(20)30314-4.

33. Mehta V, Goel S, Kabarriti R, Cole D, Goldfinger M, AcunaVillaorduna A, et al. Case fatality rate of cancer patients with COVID-19 in a New York hospital system. Cancer Discov. 2020;10(7):935-41. https://doi.org/10.1158/2159-8290.Cd-200516 .

34. Shi S, Qin M, Shen B, Cai Y, Liu T, Yang F, et al. Association of cardiac injury with mortality in hospitalized patients with COVID19 in Wuhan, China. JAMA Cardiol. 2020;5:802. https://doi.org/ 10.1001/jamacardio.2020.0950.

35. Iliescu C, Balanescu DV, Donisan T, Giza DE, Muñoz Gonzalez ED, Cilingiroglu M, et al. Safety of diagnostic and therapeutic cardiac catheterization in cancer patients with acute coronary syndrome and chronic thrombocytopenia. Am J Cardiol. 2018;122(9): 1465-70. https://doi.org/10.1016/j.amjcard.2018.07.033.

36. Jr. JLJ. March 18th, 2020. Retrieved from: https://www.acc.org/ latest-in-cardiology/articles/2020/03/18/15/25/troponin-and-bnpuse-in-covid19 Accessed 16 July 2020.

37. Stefanini Giulio G, Montorfano M, Trabattoni D, Andreini D, Ferrante G, Ancona M, et al. ST-elevation myocardial infarction in patients with COVID-19. Circulation. 2020;141(25):2113-6. https://doi.org/10.1161/CIRCULATIONAHA.120.047525.
38. Welt FGP, Shah PB, Aronow HD, Bortnick AE, Henry TD, Sherwood MW, et al. Catheterization laboratory considerations during the coronavirus (COVID-19) pandemic: from the ACC's interventional council and SCAI. J Am Coll Cardiol. 2020;75 (18):2372-5. https://doi.org/10.1016/j.jacc.2020.03.021.

39. Cammann VL, Sarcon A, Ding KJ, Seifert B, Kato K, Di Vece D, et al. Clinical features and outcomes of patients with malignancy and Takotsubo syndrome: observations from the International Takotsubo Registry. J Am Heart Assoc. 2019;8(15):e010881. https://doi.org/10.1161/jaha.118.010881.

40. Tornvall P, Collste O, Ehrenborg E, Järnbert-Petterson H. A casecontrol study of risk markers and mortality in Takotsubo stress cardiomyopathy. J Am Coll Cardiol. 2016;67(16):1931-6. https:// doi.org/10.1016/j.jacc.2016.02.029.

41. Brunetti ND, Tarantino N, Guastafierro F, De Gennaro L, Correale $\mathrm{M}$, Stiermaier T, et al. Malignancies and outcome in Takotsubo syndrome: a meta-analysis study on cancer and stress cardiomyopathy. Heart Fail Rev. 2019;24(4):481-8. https://doi.org/10.1007/ s10741-019-09773-6.

42. Desai A, Noor A, Joshi S, Kim AS. Takotsubo cardiomyopathy in cancer patients. Cardio-oncology. 2019;5:7. https://doi.org/10. 1186/s40959-019-0042-9.

43. Jabri A, Kalra A, Kumar A, Alameh A, Adroja S, Bashir H, et al. Incidence of stress cardiomyopathy during the coronavirus disease 2019 pandemic. JAMA Netw Open. 2020;3(7):e2014780. https:// doi.org/10.1001/jamanetworkopen.2020.14780.

44. Aronson D, Brenner B. Arterial thrombosis and cancer. Thromb Res. 2018;164(Suppl 1):S23-s8. https://doi.org/10.1016/j. thromres.2018.01.003.

45. Danzi GB, Loffi M, Galeazzi G, Gherbesi E. Acute pulmonary embolism and COVID-19 pneumonia: a random association? Eur Heart J. 2020;41:1858. https://doi.org/10.1093/eurheartj/ehaa254.

46. Wang DY, Salem JE, Cohen JV, Chandra S, Menzer C, Ye F, et al. Fatal toxic effects associated with immune checkpoint inhibitors: a systematic review and meta-analysis. JAMA Oncol. 2018;4(12): 1721-8. https://doi.org/10.1001/jamaoncol.2018.3923.

47. Klok FA, Kruip M, van der Meer NJM, Arbous MS, Gommers D, Kant KM, et al. Incidence of thrombotic complications in critically ill ICU patients with COVID-19. Thromb Res. 2020;191:145-7. https://doi.org/10.1016/j.thromres.2020.04.013.

48. Varga Z, Flammer AJ, Steiger P, Haberecker M, Andermatt R, Zinkernagel AS, et al. Endothelial cell infection and endotheliitis in COVID-19. Lancet. 2020;395(10234):1417-8. https://doi.org/ 10.1016/s0140-6736(20)30937-5.

49. Lippi G, Plebani M, Henry BM. Thrombocytopenia is associated with severe coronavirus disease 2019 (COVID-19) infections: a meta-analysis. Clin Chim Acta. 2020;506:145-8. https://doi.org/ 10.1016/j.cca.2020.03.022.

50. Lippi G, Favaloro EJ. D-dimer is associated with severity of coronavirus disease 2019: a pooled analysis. Thromb Haemost. 2020;120(05):876-8. https://doi.org/10.1055/s-0040-1709650.

51. Bikdeli B, Madhavan MV, Jimenez D, Chuich T, Dreyfus I, Driggin E, et al. COVID-19 and thrombotic or thromboembolic disease: implications for prevention, antithrombotic therapy, and follow-up. J Am Coll Cardiol. 2020;75(23):2950-73. https://doi. org/10.1016/j.jacc.2020.04.031.

52. Tang N, Bai H, Chen X, Gong J, Li D, Sun Z. Anticoagulant treatment is associated with decreased mortality in severe coronavirus disease 2019 patients with coagulopathy. J Thromb Haemost. 2020;18(5):1094-9. https://doi.org/10.1111/jth.14817.

53. Paranjpe I, Fuster V, Lala A, Russak AJ, Glicksberg BS, Levin MA, et al. Association of treatment dose anticoagulation with in-hospital survival among hospitalized patients with COVID-19. J Am Coll Cardiol. 2020;76(1):122-4. https://doi.org/10.1016/j.jacc.2020.05. 001 
54. Khorana AA, Kuderer NM, Culakova E, Lyman GH, Francis CW. Development and validation of a predictive model for chemotherapy-associated thrombosis. Blood. 2008;111(10):49027. https://doi.org/10.1182/blood-2007-10-116327.

55. Barnes GD, Burnett A, Allen A, Blumenstein M, Clark NP, Cuker $\mathrm{A}$, et al. Thromboembolism and anticoagulant therapy during the COVID-19 pandemic: interim clinical guidance from the anticoagulation forum. J Thromb Thrombolysis. 2020;50(1):7281. https://doi.org/10.1007/s11239-020-02138-z.

56. Darvin P, Toor SM, Sasidharan Nair V, Elkord E. Immune checkpoint inhibitors: recent progress and potential biomarkers. Exp Mol Med. 2018;50(12):1-11. https://doi.org/10.1038/s12276-0180191-1.

57. Johnson DB, Balko JM, Compton ML, Chalkias S, Gorham J, Xu Y, et al. Fulminant myocarditis with combination immune checkpoint blockade. N Engl J Med. 2016;375(18):1749-55. https://doi. org/10.1056/NEJMoa1609214.

58. Palaskas N, Lopez-Mattei J, Durand JB, Iliescu C, Deswal A. Immune checkpoint inhibitor myocarditis: pathophysiological characteristics, diagnosis, and treatment. J Am Heart Assoc. 2020;9(2):e013757. https://doi.org/10.1161/jaha.119.013757.

59. Sullivan RJ, Johnson DB, Rini BI, Neilan TG, Lovly CM, Moslehi JJ, et al. COVID-19 and immune checkpoint inhibitors: initial considerations. J Immunother Cancer. 2020;8(1):e000933. https://doi. org/10.1136/jitc-2020-000933.

60. Robilotti EV, Babady NE, Mead PA, Rolling T, Perez-Johnston R, Bernardes $\mathrm{M}$ et al. Determinants of severity in cancer patients with COVID-19 illness. medRxiv. 2020:2020.05.04.20086322. https:// doi.org/10.1101/2020.05.04.20086322.

61. Dabbagh MF, Aurora L, D'Souza P, Weinmann AJ, Bhargava P, Basir MB. Cardiac tamponade secondary to COVID-19. JACC Case Rep. 2020;458:1326-30. https://doi.org/10.1016/j.jaccas. 2020.04.009.

62. Hua A, O'Gallagher K, Sado D, Byrne J. Life-threatening cardiac tamponade complicating myo-pericarditis in COVID-19. Eur Heart J. 2020;41(22):2130. https://doi.org/10.1093/eurheartj/ehaa253.

63. El Haddad D, Iliescu C, Yusuf SW, William WN, Khair TH, Song J, et al. Outcomes of cancer patients undergoing percutaneous pericardiocentesis for pericardial effusion. J Am Coll Cardiol. 2015;66(10):1119-28. https://doi.org/10.1016/j.jacc.2015.06.1332.

64. Palaskas N, Morgan J, Daigle T, Banchs J, Durand J-B, Hong D, et al. Targeted cancer therapies with pericardial effusions requiring pericardiocentesis focusing on immune checkpoint inhibitors. Am J Cardiol. 2019;123:1351-7. https://doi.org/10.1016/j.amjcard.2019.01. 013.

65. Duan J, Tao J, Zhai M, Li C, Zhou N, Lv J, et al. Anticancer drugsrelated QTc prolongation, torsade de pointes and sudden death: current evidence and future research perspectives. Oncotarget. 2018;9(39):25738-49. https://doi.org/10.18632/oncotarget.25008.

66. Mercuro NJ, Yen CF, Shim DJ, Maher TR, McCoy CM, Zimetbaum PJ, et al. Risk of QT interval prolongation associated with use of hydroxychloroquine with or without concomitant azithromycin among hospitalized patients testing positive for coronavirus disease 2019 (COVID-19). JAMA Cardiol. 2020;5: 1036. https://doi.org/10.1001/jamacardio.2020.1834. Detailed description of the changes in QT interval prolongation for those on hydroxychloroquine and/or azithromycin.

67. Roden DM. Drug-induced prolongation of the QT interval. N Engl J Med. 2004;350(10):1013-22. https://doi.org/10.1056/ NEJMra032426.

68. Boulware DR, Pullen MF, Bangdiwala AS, Pastick KA, Lofgren $\mathrm{SM}$, Okafor EC, et al. A randomized trial of hydroxychloroquine as postexposure prophylaxis for Covid-19. N Engl J Med. 2020;383: 517-25. https://doi.org/10.1056/NEJMoa2016638.
69. Magagnoli J, Narendran S, Pereira F, Cummings T, Hardin JW, Sutton SS et al. Outcomes of hydroxychloroquine usage in United States veterans hospitalized with Covid-19. medRxiv : the preprint server for health sciences. 2020. https://doi.org/10.1101/2020.04. 16.20065920 .

70. June 15th, 2020. Retrieved from: https://www.fda.gov/newsevents/press-announcements/coronavirus-covid-19-update-fdarevokes-emergency-use-authorization-chloroquine-and\#: :text= Today the U.S. Food and,clinical trial was unavailable or. Accessed 15 July 2020.

71. Beigel JH, Tomashek KM, Dodd LE, Mehta AK, Zingman BS, Kalil AC, et al. Remdesivir for the treatment of Covid-19 - preliminary report. N Engl J Med. 2020. https://doi.org/10.1056/ NEJMoa2007764.

72. Sturgeon KM, Deng L, Bluethmann SM, Zhou S, Trifiletti DM, Jiang C, et al. A population-based study of cardiovascular disease mortality risk in US cancer patients. Eur Heart J. 2019;40(48): 3889-97. https://doi.org/10.1093/eurheartj/ehz766.

73. Bobrowski D, Suntheralingam S, Calvillo-Argüelles O, Michalowska M, Amir E, Sacha Bhatia R, et al. The yield of routine cardiac imaging in breast cancer patients receiving trastuzumab-based treatment: a retrospective cohort study. Can J Cardiol. 2019. https://doi.org/10.1016/j.cjca.2019.12.021.

74. Calvillo-Argüelles O, Abdel-Qadir H, Ky B, Liu JE, Lopez-Mattei JC, Amir E, et al. Modified routine cardiac imaging surveillance of adult cancer patients and survivors during the COVID-19 pandemic. JACC CardioOncol. 2020;2(2):345-9. https://doi.org/10.1016/j. jaccao.2020.04.001

75. Wang Z, Wang J, He J. Active and effective measures for the care of patients with cancer during the COVID-19 spread in China. JAMA Oncol. 2020;6(5):631-2. https://doi.org/10.1001/ jamaoncol.2020.1198.

76. Tam CF, Cheung KS, Lam S, Wong A, Yung A, Sze M, et al. Impact of coronavirus disease 2019 (COVID-19) outbreak on STsegment-elevation myocardial infarction care in Hong Kong, China. Circ Cardiovasc Qual Outcomes. 2020;13(4):e006631. https://doi.org/10.1161/circoutcomes.120.006631.

77. June $\mathrm{CH}$, Sadelain M. Chimeric antigen receptor therapy. N Engl J Med. 2018;379(1):64-73. https://doi.org/10.1056/ NEJMra1706169.

78. Lee DW, Gardner R, Porter DL, Louis CU, Ahmed N, Jensen M, et al. Current concepts in the diagnosis and management of cytokine release syndrome. Blood. 2014;124(2):188-95. https://doi.org/10. 1182/blood-2014-05-552729.

79. Le RQ, Li L, Yuan W, Shord SS, Nie L, Habtemariam BA, et al. FDA approval summary: tocilizumab for treatment of chimeric antigen receptor $\mathrm{T}$ cell-induced severe or life-threatening cytokine release syndrome. Oncologist. 2018;23(8):943-7. https://doi.org/ 10.1634/theoncologist.2018-0028.

80. Aziz M, Fatima R, Assaly R. Elevated interleukin-6 and severe COVID-19: a meta-analysis. J Med Virol. 2020. https://doi.org/ 10.1002/jmv.25948.

81. Guaraldi G, Meschiari M, Cozzi-Lepri A, Milic J, Tonelli R, Menozzi M, et al. Tocilizumab in patients with severe COVID19: a retrospective cohort study. Lancet Rheumatol. 2020;2(8): e474-e84. https://doi.org/10.1016/S2665-9913(20)30173-9.

82. July 31 st, 2020 . Retrieved from https://clinicaltrials.gov/ct2/results? cond $=$ Covid $19 \&$ term $=$ tocilizumab $\&$ cntry $=\&$ state $=\&$ city $=\&$ dist $=$ $\&$ Search=Search. Accessed 31 July 2020.

Publisher's Note Springer Nature remains neutral with regard to jurisdictional claims in published maps and institutional affiliations. 